\title{
El trazo de los otros: Jaime Torres Bodet y Elías Nandino frente a Contemporáneos ${ }^{*}$
}

\section{Horacio Molano Nucamendi**}

\section{Resumen}

Tiempo de arena (1955) de Jaime Torres Bodet y Juntando mis pasos (2000) de Elías Nandino son dos obras autobiográficas en las que sendos autores hacen una evaluación crítica de algunos miembros de Contemporáneos; ambos describen tanto sus rasgos físicos como las características de su personalidad. Analizar y comparar la forma en que los dos autobiógrafos representan a sus compañeros es el objetivo de este artículo. La cercanía permite esbozar la interioridad de algunos de los miembros del grupo.

Palabras clave: Retrato literario, Contemporáneos, Representación, Autobiografía mexicana.

\section{Tracing others: Jaime Torres Bodet and Elías Nandino in front of Contemporáneos}

\begin{abstract}
Tiempo de arena (1955) by Jaime Torres Bodet, and Juntando mis pasos (2000) by Elías Nandino are two autobiographical works in which both authors make a critique of some members of Contemporáneos, which includes a description of their physical and personality traits. This article aims to analyze and compare the way in which both autobiographers describe their fellows. Closeness makes it possible to sketch the interiority of some of the members of the group.
\end{abstract}

Keywords: Literary portrait, Contemporáneos, Depiction, Mexican autobiography.

\footnotetext{
* Este artículo se inscribe en el Proyecto de Investigación "Procesos de la construcción del yo en la escritura autobiográfica en México". Proyecto PAPIIT, IN404516, Dirección General de Asuntos del Personal Académico (DGAPA), UNAM.

** Mexicano. Doctor en Letras por la Universidad Nacional Autónoma de México. Académico del Centro de Enseñanza para Extranjeros de la UNAM, Ciudad de México, D.F., México.hmolano@unam.mx
} 


\section{La complicidad de Contemporáneos}

La libertad entrañada en los rumbos literarios de los jóvenes pertenecientes al grupo Contemporáneos -de los años veinte y treinta del siglo pasado- se aprecia como un momento cumbre de las letras mexicanas. Los integrantes de dicha generación "fueron acusados en su tiempo (en una de las polémicas más pasmosas de la crítica mexicana) de ejercer una literatura extranjerizante y 'poco viril', aunque han sido valorados luego como ejecutantes y disparadores de un canon renovador, sobre todo en lo que respecta a la poesía y ensayo modernos" (Toledo 226). La lista de nombres nunca ha sido unánime, no obstante de acuerdo con "la superficialidad del análisis de sus componentes, vistos sólo desde la poesía, incluye con cierta relatividad a Carlos Pellicer, Jaime Torres Bodet, José Gorostiza, Bernardo Ortiz de Montellano, Enrique González Rojo, Jorge Cuesta, Xavier Villaurrutia, Elías Nandino, Salvador Novo y Gilberto Owen" (Schneider 80). Para comprenderlos es fundamental saber que se congregaron alrededor de un proyecto cultural como lo fue la revista Contemporáneos (1928-1930)', que les dio su nombre, pues "al acelerar la historia y al proponer el gusto, las revistas literarias producen una zona de combatividad de enorme potencial creativo. Las revistas producen más simpatía o antagonismos que los que producirían sus partes aisladamente; demarcan territorios estéticos o ideológicos asibles y manejables" (Sheridan 366). Por ello es crucial la época, ya que están conscientes de la función social de ese vehículo difusor de ideas que procura la incorporación de México en el mundo:

El desafío del grupo fue asumido a plenitud y desbordó el ámbito literario. Su actitud renovadora, su afán de contemporaneidad, su exigencia, su abierto desplante, su insolencia, su talento y su inusitada y precoz inteligencia fueron apenas los ingredientes necesarios para irritar a una corriente nacionalista que se volvió dogmática e intolerante al identificar ciertas formas de expresión [...] Luego del enfrentamiento (algo de quema de brujas tuvo), la frágil aventura colectiva concluyó y cada quien, de muy diversa forma, continúo su vía. (Fernández Perera133)

1 Ésta fue quizá la publicación periódica de mayor repercusión en el medio intelectual de la época, aunque antes ya habían editado La Falange (1922-1923) y Ulises (1927-1928) y, posteriormente, Examen (1932). 
Según Octavio Paz (1994), a pesar de haber sido "cosmopolitas en materia de arte, fueron patriotas convencidos [...] su mexicanismo, en el polo contrario al de Diego Rivera, no era folcklórico ni ideológico sino una manera de ser a un tiempo severa, reservada y cortés" (79). La incomprensión en su momento se transformó después en estimación de sus declaraciones y propuestas, por lo que su actitud "resulta ejemplar de lo que una sociedad literaria transparenta en su matriz civil" (Espinasa 29). De ahí que "el carácter dialéctico y apasionado de la escritura" se considere como "común denominador de ese fenómeno llamado Contemporáneos" (Quirarte 31). José Joaquín Blanco enuncia en su recuento de los años veinte de las letras mexicanas las cualidades de aquellos autores: "cultos, rigurosos, críticos, valientes, armados de una asombrosa rebeldía intelectual, estética y moral. Escandalizaron y se vieron perseguidos; también recibieron el asombro, la admiración y hasta (a ratos) el mecenazgo oficial" (Fernández Perera 111).

En consecuencia, detenerse en la escritura autobiográfica de dos de ellos será relevante para construir las imágenes personales de quienes conformaron 'el 'archipiélago de soledades' que Torres Bodet percibió, el 'grupo sin grupo' al que se refería Villaurrutia, o el 'grupo de forajidos' que, para Cuesta, unía felizmente a sus amigos, nos marca de manera indeleble [...] porque, a su vez, marcó en buena lid las circunstancias dentro de las que se realiza la tarea cultural del México contemporáneo" (Sheridan 11). Por tal motivo, descubrir las huellas que dejaron esas presencias tanto en la memoria de Jaime Torres Bodet como de Elías Nandino plantea la necesidad de referirse al retrato literario.

Dentro de la tradición mexicana, Víctor Díaz Arciniega (1989) apunta a que son dos las vías de aquel género: la vertida "en escritos periodísticos de ocasión y en las recordaciones asentadas en diarios y memorias" (65), es decir, si se hace pública inmediatamente o si se conserva en el ámbito privado. Asimismo considera significativo que se descubra "al hombre común y cotidiano” (66). Al comentar el trabajo de Gutiérrez Nájera y Luis G. Urbina concluye que el retratista "se deja llevar por las imágenes y las alusiones donde la evocación sentimental y la invocación intelectual son una sola unidad" (76). Advierte cómo Riva Palacio y Nervo hacen de la semblanza un recurso crítico, pues "se integran al retrato del individuo las cualidades de su obra y de su personalidad” (82), también señala cómo, dentro de las escrituras del yo, el retrato literario se convierte en "punto de apoyo para análisis y evocaciones; su fin no está en sí mismo, sino en 
su carácter de complementariedad de un conjunto" (82). Los autobiógrafos aquí estudiados fusionan esas dos prácticas como se apreciará en los ejemplos más adelante.

La definición clásica de retrato literario es aquella que une la prosopografía con la etopeya, vale decir, la descripción tanto de rasgos físicos como de las cualidades internas que brindan un perfil psicológico o moral de la persona. Por lo tanto, se traza la impresión externa de un individuo a la vez que se refiere cómo es en su interacción social. A pesar de que aparentemente estas figuras retóricas se oponen, comparto la siguiente idea: "es difícil que el retrato externo no deje transparentar algunos rasgos del carácter del retratado" (Marchese 334). Debido a que la apariencia en la mayoría de los casos se convierte en reflejo de atributos del carácter.

Margarita Iriarte López (2004) plantea la necesidad de ver al retrato literario como un género propio en el cual se manifiesta una entidad textual cuyas dimensiones adquieren un uso más allá de la mera técnica de elaborar un tipo de texto. Más que un procedimiento al observar a alguien se trata de un paradigma de configuración literaria en la cual se plasma "una interiorización más radicalmente vivencial" (278). Por consiguiente, el retrato supone "una contemplación detenida, morosa, bastante menos lógica-argumentativa que meramente delecto-demostrativa. La motivación es distinta y ello incide en su configuración y naturaleza final" (279). Este modo de apreciar la labor del trazo de los otros es el que se ajusta al valorar las presencias de los Contemporáneos en las autobiografías de Jaime Torres Bodet y Elías Nandino, quizá con mayor fuerza en este último, en cuya estructura capitular de Juntando mis pasos se hace evidente. En cambio, en el primero, se privilegia la contemplación en conjunto de sus compañeros. No obstante, ambos materializan en sus páginas el hecho de ser cómplices con sus retratados al compartir anhelos de juventud.

\section{Ante la mirada de Jaime Torres Bodet}

Gran parte del primer volumen autobiográfico de Jaime Torres Bodet, Tiempo de arena (1955) lo dedica a escribir sobre los otros². Sin duda, un momento crucial en su vida fue el encuentro con los futuros integran-

2 Rafael Olea Franco (1994) apunta que, "Tiempo de arena se ubica en medio de los dos extremos propios del género: la crónica pura escrita en forma de memorias en las que el autor está casi ausente, o bien las autobiografías religiosas o místicas" (81). 
tes de Contemporáneos. El capítulo XII está consagrado a "Poetas en la Escuela", donde la entrada al Colegio de San Ildefonso fue el paso decisivo para encontrar su vocación literaria. La influencia de estos compañeros la señala como un estímulo que se produjo "más de prisa” o que caló "de manera más honda" (231) en dicha vocación.

El primero en esta galería es Carlos Pellicer, ambos comparten la cátedra de "Lectura y Declamación” impartida por el profesor Tovar y Ávalos con quien se adentran en las "páginas de Quevedo y de Castelar, el Idilio de Núñez de Arce, algunos romances del Duque de Rivas y, naturalmente, las Rimas de Bécquer". Asimismo “ciertos fragmentos de Calderón -el monólogo de La vida es sueño- o determinados poemas de José Asunción Silva y de Rubén Darío" (232). Su condiscípulo es descrito con precisión:

Era Carlos, en esos días, un joven pálido y atildado, de mirada profunda, cejas gruesas y palabra cálida, varonil. La calvicie, a partir de los 30 años, ha dado a su cabeza una desnudez de patricio estoico, cincelada para los lauros. Entonces, aquella parquedad incipiente parecía solo un pretexto, que el peluquero aprovechaba para peinarlo con pulcritud. (232)

La autobiografía de Torres Bodet se goza por la delicada visión de un pasado entrañable que se reconstituye mediante un pulcro y certero lenguaje. Cada vocablo se escoge para caracterizar a un Pellicer que fue con el tiempo amigo inseparable y poeta venerado. El aspecto físico descubre el interior de la persona, de ahí que estemos ante el retrato literario ejercido con habilidad. La nobleza externa permite referirse al trato suave y afectuoso. Es en el detalle donde se encuentra al individuo: "como sus poemas, lo primero que su persona manifestaba eran los adjetivos: la corbata de seda espesa, los calcetines brillantes; y, en el meñique, un espléndido solitario" (232).

El juicio sobre su obra es contundente: "Pellicer es considerado ahora, muy justamente, como el poeta de América. Su abundancia verbal constituye uno de los lujos de nuestro Continente". Se adentra en sus cualidades luminosas: "su actitud poética más genuina es la oda, su temperatura normal la fiebre, su colaborador incansable el sol” (232). De ahí que sea significativo el relato de la ocasión en que recitó varias "marinas" en clase, pues al joven Jaime lo dejó vivamente impresionado: "La música y el color eran las cualidades de esos poemas. Las metáforas se despegaban, a veces, del fondo de la composición; en ocasiones, la unidad del asunto pasaba a segundo término... Pero ¡cuántas plásticas sugestiones conte- 
nían aquellos alejandrinos!" (232). El recuerdo de ese momento revela la oportunidad única de compartir el aula con semejante talento. Más adelante muestra a Pellicer como un ejemplo de dedicación literaria a pesar de asistir a sus cursos en la Escuela de Jurisprudencia. Por aquellos días de 1918 el poeta tabasqueño emprendería una misión diplomática a Sudamérica:

La idea del viaje que le esperaba nos hacía considerarlo ya como ausente. Por ese sólo hecho nos parecían sus versos más armoniosos, menos sonoras sus carcajadas. La noticia de su alejamiento probable hacía con su persona lo que -por fortuna- no ha conseguido la fama con su lirismo: quitarle el peso del colorido suntuoso, traducirla del idioma del trópico al de la altiplanicie, dibujarla ya no con tintas de tonos vivos, sino con ese fino y abstracto lápiz con que él soñara, años más tarde, “escribir su meditación”. (244)

Valoración certera de las propiedades de un material poético que ha trascendido al paso de los años. Este es un buen ejemplo de cómo a la par de fijar el detalle de la persona se realiza un juicio crítico de la obra.

Más tarde, en 1921, Torres Bodet fue secretario particular de José Vasconcelos, quien en ese momento era Rector de la Universidad de México e ideaba una iniciativa federal de educación. Para alcanzar los fines de un plan nacional de enseñanza -uno de los pilares de la Revolución- se organizaron viajes al interior de la república con la finalidad de exponer sus bases en los cuales coincidieron Carlos y Jaime.

Contrasta Torres Bodet las personalidades de Pellicer y José Gorostiza, quien manifestaba "un orgullo de hombre lúcido y sentencioso" (233). Se siente más afín con el último, pues según señala: "como yo, se inclinaba a los medios tonos. Por desgracia, esa predilección en común no deparaba a mis versos la sutileza que, en sus poemas, hubo de impresionarme. Porque, apenas le conocí, me propuse enseñarle mis producciones. Aunque con reservas, él también, me hizo juez de las suyas: raras en número, exquisitas de calidad" (233). Lo pinta, además, en los siguientes términos: "delgado y frágil, vestía de negro o de azul oscuro. A diferencia de Pellicer, no usaba nunca sino corbatas y frases imperceptibles. De pronto, advertíamos sus amigos que la tela de aquéllas era excelente y que, en los pliegues de éstas -lentos y suaves se hallaba oculto un alfiler incisivo, de intelectual" (233). Nuevamente, el cuidado externo refleja la cara íntima, aunque importe más dar cuenta de su proceso creativo: 
Exigente consigo mismo más que con sus iguales, producía poco; no por esterilidad, según lo creyeron más tarde críticos impacientes, sino por ansia de clásica perfección. El poema se formaba lentamente en su inteligencia, merced a una técnica mineral que iba depositando sobre el núcleo a veces mínimo del asunto láminas sucesivas; primero opacas como el carbón, luminosas al cabo como el diamante. (233)

De este modo, José Gorostiza encuentra el estilo de su práctica poética. Remata Torres Bodet con la siguiente oposición: "lo que era ya en Pellicer gozosa germinación, entre loros y lianas de selva virgen, resultaba en él cristalización, de alquimias críticas invisibles" (233). Así, esos procedimientos dispares van caracterizando la variedad literaria de una generación que valora el encuentro de la expresión de una voz propia.

Cada uno de nosotros parecía destinado a servir de imagen a una de las formas que Pascal analiza en su arte de persuadir. Según él, la verdad puede ser objeto de tres propósitos. El de descubrirlo, si se la busca. El de demostrarla, si se la tiene. Y, para quien se propone juzgarla, el de discernirla. Villaurrutia se sentía inclinado a lo segundo. Gorostiza tenía aptitudes para lo último. Yo me confesaba deseoso de lo primero (292-293).

Las rutas creativas son individuales, aunque la cercanía de algunos con otros se hacen evidentes. "José Gorostiza compartía no pocas de mis incertidumbres -poéticas y vitales" (292), aunque "había en su obra todo un sector que la música atravesaba. Pero, inclusive ahí, su talento se defendía de los sentidos, limitándolos, decantándolos y procurando filtrarlos conscientemente" (292). Insiste Torres Bodet en su "método intelectual" debido a su "voluntad de estructura".

Continúa el panorama de "Poetas en la Escuela" con alguien "de sensibilidad subterránea" (235), se trata de Bernardo Ortiz de Montellano con quien se identificaba por la fuerte presencia materna y el hecho de ser ambos originarios de la Ciudad de México. Esas semejanzas en un primer momento los alejaron, pero a la larga terminaron por estrechar sus lazos. Dice el autobiógrafo: "Por capitalinos, padecíamos ambos el mal de la desconfianza. ¿No fue Pedro Henríquez Ureña quien mejor definió al hombre del altiplano: una lija, cubierta por un papel de seda? Acaricia su primer roce. Pero la mano de quien insiste sangra a menudo" (235). Era susceptible a la opinión ajena, pues "en la palabra menos inten- 
cionada creía descubrir una crítica" (235). Gracias a él descubrió autores como Francis Jammes y Juan Ramón Jiménez; "era Nervo su dios mayor" debido a "aquel tono sentimental, de confesionario laico, que instala a muchos de sus poemas en el ambiente de una supuesta conversación entre el hombre de letras y sus lectores" (235). Por otra parte, "era en extremo religioso" y "vivía [...] junto con su madre y su única hermana" (235). Concluye la rememoración de su amigo en el mencionado capítulo: "yo mismo habré de fijar aquí sólo su imagen de adolescente... Pero quienes le hayan seguido hasta el término de su vida comprenderán la emoción con que veo pasar sus sombra sobre las páginas de este libro, que me hubiera agradado tanto ofrecer a su juicio íntimo y fraternal" (235). Sin duda fue alguien muy querido.

Declara abiertamente: "en cuanto a Bernardo, el más cercano y constante de mis amigos, su deseo de autenticidad irrestricta lo situaba en un plano difícil y silencioso" (293). Valora como el mejor de sus libros Sueños. Las preferencias artísticas de su amigo son claramente identificadas, pues, por ejemplo, se inclinaba por "el 'color local'. Saturnino Herrán había sido, para su adolescencia, lo que Amado Nervo en la lírica. En los dos hallaba ese ambiente de religiosidad provincial y de recoleto mexicanismo que era, entonces, el suyo propio" (331).

Se suman a este recuento de presencias Salvador Novo y Xavier Villaurrutia, quienes eran un poco más jóvenes y se referían a los ensayos literarios de don Jaime con indulgencia. Señala que "ambos -como yo mismo- escribían poemas en cuyas estrofas se duplicaba, con diferentes refracciones temperamentales, la luz del atardecer simbolista francés. Ambos continuaban la obra de Enrique González Martínez; pero, sin decírmelo, se impacientaban un poco de continuarla" (256). Al parecer, la seguridad y la confianza de aquel dúo daban la impresión de aparente complacencia hacia los demás. La diferencia entre ellos, no obstante, radicaba en que:

Novo, más humano y menos estricto que Villaurrutia, usaba en aquellos años una cabellera que la vida le ha dado derecho a recuperar; ${ }^{3}$ obtenía de sus maestros más venerables, como don Ezequiel, consejos que comentaba con irónico escepticismo y nos sorprendía a todos por la plasticidad de una inteligencia que, a fuerza de ser flexible, parecía dócil, pero que no abando-

3 Durante los últimos años de su vida fueron famosas las pelucas con que se acicalaba. 
naba jamás las aptitudes intransferibles que habrían de constituir, con el tiempo, su mejor mérito. (256)

Torres Bodet da muestra de una sagacidad a prueba de fuego en su correspondencia. Transcribe párrafos de sus cartas en las que se pregunta si son ya muestra de "la prosa rápida, lógica y humorística, que reconocen los lectores actuales en las páginas de su madurez" (Torres Bodet 257). Rememora su curiosidad por ciertos líricos norteamericanos que lo lleva a traducir a Lee Masters, donde señala "todavía hoy descubro trozos de eficacia poética incuestionable" (257). Su impecable dominio de la lengua, tanto en poesía como en prosa, hace indicar al autobiógrafo que:

lo que más aprecio en su producción es la unidad mantenida entre sus dos formas expresivas; unidad que impone a ciertas páginas en verso la levedad sonriente de sus artículos, estenografía feliz de la realidad, y que impregna algunos de sus libros en prosa con esa ternura humana -que debería dejar más en libertad, para ser siempre fiel consigo mismo. (258)

\section{Cierra así el juicio crítico de este Contemporáneo.}

Sobre Xavier Villaurrutia abunda en su tendencia a la abstracción. De él se indica que se deleitaba "en construir, como los cubistas, paisajes abstractos con formas y volúmenes muy concretos" (258). Sin duda, formaba parte de la expresión artística del momento en que las vanguardias proponían nuevas vías de bosquejar el mundo circundante.

Luego coincidieron en el trabajo en la Secretaría de Salubridad -dirigida por el doctor Bernardo Gastélum- donde también trabajaron Enrique González Rojo, José Gorostiza y Bernardo Ortiz de Montellano, con quienes formaron un grupo de lectura y, al ser Villaurrutia el más joven, se señala: "su influencia se hizo más perceptible. Su figura aparece, en la pantalla de mis recuerdos, como la de un interlocutor sumamente agudo, entre cuyos labios la sonrisa parecía en seguida un consejo crítico. Algo había de reticente en su aplauso y de tácito hasta en su voz. Penetraba sin ruido en los aposentos que se le abrían" (291). De nuevo el aspecto físico es revelación de la interioridad de la persona. Evoca aquel trato familiar al compartir el espacio laboral:

En mi despacho, cuando iba a verme, permanecía a menudo de pie, junto al marco de la ventana que daba sobre el Paseo de la Reforma, o a la vera de alguna mesa. Los libros del estante inmediato y el pisapapel o la regadera del escritorio eran -bajo 
sus manos- lo que el pañuelo, los guantes o el cigarrillo en los de algunos actores: un elemento de expresión indirecta, un recurso de espera para la réplica y, más que nada, una comprobación feliz de la realidad. (291)

La atmósfera de aquella escena refiere la cotidianidad de su trato. Define a Villaurrutia como un asiduo lector, pero disperso. Por el contrario, Torres Bodet perfila sus lecturas en orden cronológico buscando primero a los clásicos y luego a las novedades. En cambio, Xavier esparcía sus gustos sin hacer ostensible las relaciones entre un autor y otro. "La imaginación, los sentidos, los sentimientos, disimulan y excusan la inteligencia. En Villaurrutia, nada material atenuaba el contacto directo con el talento" (292). Más adelante, deja en claro esas posturas encontradas: "buscaba un lirismo que no se apoyará lánguidamente sobre una base tradicional. Hacía bien en buscarlo. Y nunca me presenté yo ante él como un defensor de la herencia y de la costumbre" (316). Sin embargo, fija sus ideas al respecto al calificar los "Nocturnos" como una conciliación entre el poeta y el hombre (316) y como una iluminación profunda conseguida por cierta afición más al dibujo que al color (257-258).

A Gilberto Owen se le menciona en una discusión sobre la naturaleza de la poesía ${ }^{4}$, pues dentro del grupo había dos posiciones encontradas: aquellos a favor de la práctica "pura" de ésta, confrontados contra quienes volcaban en ella la experiencia -calificados por los primeros de anecdóticos-. Para Torres Bodet estaba claro: “No opongamos -pedía yo- a la poesía humana, de ayer, de hoy, de siempre, la poesía sin hombre, sin poeta, sin poesía"' (317). Al parecer tanto Owen como Villaurrutia, en ese tiempo de juventud, creían en el "arte puro", aunque se advierte que después acabaron por darle la razón a Torres Bodet quien propugnaba por sacudirse "el adorno falso, la retórica imitada, el insolente lujo verbal" (317). Dicho capítulo lleva por nombre "La deshumanización del arte", en referencia clara al libro de Ortega y Gasset, y vierte ahí el autobiógrafo sus ideas sobre la belleza y la práctica poética que no pueden desvincularse "del sentir humano" (315).

Otro capítulo que evidencia el intenso intercambio de lecturas e ideas es el XXVII “Lecturas en Salubridad”, donde varios de los Contemporáneos trabajaron. Ahí bosqueja el perfil de Enrique González Rojo: "su optimis-

4 Véase Anthony Stanton. "Los Contemporáneos y el debate en torno a la poesía pura". Los Contemporáneos en el laberinto de la crítica. México, El Colegio de México, 1994, pp. 27-43. 
mo, sus viajes (había ido a Europa y a Chile) y sus lecturas le abrían el alma a un horizonte de facilidad y de comprensión tolerante, que nosotros no concebíamos, pero que le hacía, en el fondo, más simpático y más humano" (293). Resume así el temperamento de su amigo. En el capítulo XXXVII dedicado a la revista “Contemporáneos", vuelve a insistir en su faceta de viajero pues "en aquella expedición al Viejo Mundo había visitado el Louvre, la galería Rodin y las incomparables salas del Prado. Nos describía con efusión a los esclavos de Miguel Ángel y exaltaba, cada vez que podía, la estatuaria dramática de Bourdelle" (331). Además, en su paso por Madrid, había podido conocer a figuras "de quienes pronunciábamos todavía los apellidos con escolar subordinación”: "Unamuno, Machado, Ortega" (331). En un plano más íntimo recuerda a "González Rojo -que me había acompañado a los 15 años, en la pasión por las óperas- no renunciaba a Mozart, y menos aún a Rossini; pero se decía más atraído por la escultura. Coleccionaba álbumes y catálogos de museos" (331). La cultura y la admiración de la belleza eran actividades compartidas dentro del grupo y que en un intento por vigorizar al México post-revolucionario encontraron su medio idóneo en el proyecto de una revista.

Con la finalidad de fundar una nueva publicación el grupo de amigos realizó un diagnóstico de las publicaciones periódicas del momento; europeas, como Le Mercure de France, la Nouvelle Revue Française y la Revista de Occidente; y latinoamericanas, como la argentina Nosotros, la chilena Atenea, la cubana Avance o la costarricense Repertorio Americano, y decidieron crear un órgano difusor de "las realizaciones europeas y las promesas americanas” (331). De tal suerte, “nació Contemporáneos, gracias a la intrepidez del doctor Gastélum y a la voluntad de unos cuantos jóvenes, que no se daban cuenta muy clara de las robustas antipatías que su intolerancia imprudente tendría que suscitar" (331). A pesar de que en su momento ellos no tenían la intención de reunirse de forma sectaria, desde fuera se los apreciaba así. Jaime Torres Bodet reflexiona sobre el ánimo que los movió a reunir sus esfuerzos: "El nombre que elegimos -Contemporáneos- no tenía nada de doctrinario. En efecto, la unidad de nuestro pequeño grupo no obedecía tanto a la disciplina de una capilla cuanto a una simple coincidencia en el tiempo: a eso que algunos llaman la complicidad de una generación" (332). Señala "el rigor con que desechábamos ciertos originales -o defendíamos ciertos manuscritos-, hubimos de dar, sin quererlo la impresión de una dura homogeneidad. Se nos acusó de constituir una academia de elogios mutuos..." (332). 
Asevera que basta una revisión de los números para desmentir esa última afirmación. Sobre la naturaleza de su unión afirma: "Nos sabíamos diferentes; nos sentíamos desiguales. Leíamos los mismos libros; pero las notas que inscribíamos en sus márgenes rara vez señalaban los mismos párrafos. Éramos, como Villaurrutia lo declaró, un grupo sin grupo. O según dije, no sé ya dónde, un grupo de soledades" (332). Se acentúan las rutas individuales.

Eso en cuanto a una explicación colectiva, ya que cuando explora una definición de sí mismo se contrasta con Porfirio Barba Jacob en los siguientes términos:

No tardamos en comprender que entre ambos se levantaría constantemente una barrera insalvable. De prejuicios burgueses, creía él. De sensibilidades opuestas, pensaba yo. Desde chico, me había enseñado mi madre preferir las dificultades a los placeres, las privaciones a los excesos -y a no gustar de ninguna dicha sino escanciada en la copa de un acto puro. (248)

Es significativo el título del capítulo destinado al escritor colombiano: “Aparición del inmoralista", con el cual subraya ese distanciamiento de posturas ante la vida. No cabe duda que Barba Jacob era un dionisíaco y Torres Bodet un apolíneo. Fue en casa de Enrique González Martínez donde se produjo aquel encuentro, pues ahí realizaban tertulias animadas por Enrique González Martínez hijo y con la indulgencia de doña Luisa, esposa del primero y madre del segundo. Destaca la sobriedad y la contención como características propias", frente a las de aquel "desterrado a perpetuidad" (247), quien se refugiaba en el alcohol y la adrenalina de sus impulsos. No extraña entonces que exprese así la discrepancia: “Tenía que contrariarme, por tanto, la impaciencia de aquel magnífico insatisfecho para quien ser ofrecía una sola continuidad: la del vértigo del deseo" (248). En oposición a éste contemporáneo, él se caracteriza como prudente y sosegado. El trato con aquellos bohemios refuerza en Torres Bodet sus valores más tradicionales. Ante la heterodoxia de aquel pensamiento se reafirmaba su proclividad conservadora. Es notorio en este caso cómo referirse a los demás es al mismo tiempo una estrategia para darse a conocer a sí mismo.

5 "De esta filosofía proviene la austeridad que rige gran parte de las actitudes vitales del escritor y que incluso en ciertos momentos refrena sus entusiasmos" (Olea Franco 83). 


\section{A un paso de distancia: desde la memoria de Elías Nandino}

El reconocimiento por parte de Elías Nandino de su condición homosexual se plantea desde el prefacio de Juntando mis pasos (2000) y muestra cómo el grupo de Contemporáneos fue estigmatizado por tal motivo. Expresa el poeta jalisciense: "Yo tenía conciencia de mi heterodoxia sexual, pero mi anhelo de vivir la vida como yo quería me hizo olvidar los riesgos, y al conocer a Xavier Villaurrutia, a Salvador Novo y a Carlos Pellicer, conseguí mi prestigio y desprestigio, porque ya ellos estaban señalados como homosexuales" (XVI). El ambiente en México ha sido francamente hostil a la afirmación de la orientación lésbica o gay, ${ }^{6}$ Nandino lo sabía de primera mano, pues en su práctica como médico dice:

No me escandalizaba, lógicamente, pero sí me pesaba el dolor y el sufrimiento de tanta gente condenada a guardar en secreto su vida. Hombres casados que hacían hijos por cumplir con su mujer [...] Lo mismo mujeres casadas, que casi enloquecidas iban a pedir auxilio por el pavor y el odio que les daba tener que acostarse con sus maridos. También atendía homosexuales que no querían serlo y juzgaban como una vergüenza sus desahogos sexuales. (XVII)

Aquellos conflictos expresados por sus pacientes lo obligan a reflexionar sobre sus propias circunstancias y poco a poco reafirma su identidad sexual dejando de lado los típicos prejuicios en torno a lo diferente. Sin embargo, en un inicio tuvo reservas al socializar con aquellos escritores tan trasparentes en sus gustos. Fue hasta escribir el poema "Autodefensa" que confiesa: "yo me absolví a mí mismo, en que me retiré la sensación del pecado y empecé a considerar natural mi manera de vivir" (XVI).

Nandino señala a Salvador Novo como alguien que hacía gala más notoriamente de su preferencia. De hecho, al finalizar el capítulo dedicado a él, narra cómo acudieron a una reunión ofrecida por una señora cubana y al ser interrogado por la hermana de la anfitriona consigna el siguiente diálogo: “'Ay, señor, por favor tome algo, haga algo”, y como no lo conocía, le preguntó: ‘¿Usted qué es?', y Novo le contestó inmediatamen-

6 “Si la homosexualidad de varios integrantes de los Contemporáneos los sitúa como ejemplos de valentía moral, en especial el Novo provocador, su poesía amorosa, leída por la posteridad, es mucho más que una literatura gay en un momento de machismo exacerbado" (Espinasa 34). 
te: 'Joto.' La señora abrió más los ojos, se avergonzó y le pidió: 'Entonces no haga nada, por favor"' (Nandino 74). Esta anécdota indica lo incisivo que Novo solía ser. El autor de Juntando mis pasos reconoce: “eso sí: era divertidísimo; tenía un ingenio tremendo. Cuando lo acompañaba en el coche, siempre en las esquinas, si veía que el gendarme era guapo, se acercaba, le pedía que lo infraccionara y le daba una tarjeta con su teléfono" (72). Este par de anécdotas son ilustrativas de su carácter extrovertido. La ambivalencia al juzgar su personalidad se expresa más adelante en estos términos: "Intelectual y mordazmente era el más atrevido del grupo, y se valía de su cuerpo y de su fama para cierto cinismo exagerado. $\mathrm{Su}$ afeminamiento era un poquito ridículo, como si un elefante quisiera hacer jotería" (72).

En el capítulo consagrado a una mirada de conjunto de los Contemporáneos, Nandino es directo al señalar: "Salvador, cínico, procaz, desvergonzado, gracioso, irónico y con una lengua viperina, nos divertía con sus chistes o con lo que nos contaba de sus 'cueros.' Coqueteaba con los hombres como si él fuera una mujer, y nosotros éramos discretos" (6o). De esa manera expresa cierto desdén por el rol pasivo que aparentemente Novo hacía obvio. De hecho, dos capítulos más adelante, Nandino retrata su carácter: "en lo particular, Novo era difícil. Todo lo enfadaba y el fastidio fue un gran compañero de su vida. En realidad, nunca tuvo un amigo íntimo. El chiste mordaz o la ofensa baja estaban a flor de labio en él" (71-72). Entonces, el disgusto lo causa la acidez en su trato y el aislamiento que prodigaba el autor de Nueva grandeza mexicana (1946).

Al realizar su prosopografía anota: "Salvador era horrendamente feo y, ya de viejo, su figura se perdió en joroba, altura y barriga” (71). De hecho, cuando Rafael Solana se vio obligado a regresarle un golpe, refiere Nandino que este último afirmó que “'sencillamente sentí como si le pegara a la manteca"' (72). Queda claro el desagrado por el cronista mexicano de parte de nuestro autobiógrafo. No obstante, distingue entre el joven y el viejo al plasmar la imagen de Novo desde una primera impresión: "abrió un señor alto, delgado, como víbora parada, un poco torcido y con el cabello alborotado" (59). Posteriormente con la edad "se hizo gordo, acromegálico, jorobado, con su rostro deforme y, para colmo, calvo. Tuvo que usar peluca, y no solamente negra, sino de todos colores. En realidad le gustaba llamar la atención" (6o). Es la construcción del cronista de la Ciudad de México que se propuso influir en la opinión pública construyéndose una imagen estrafalaria, pues de esta forma conseguía 
sacudir los códigos de buen gusto dictados por los conservadores. Al principio del capítulo se pone al descubierto su vínculo afectivo: "Salvador Novo fue muy amigo mío al principio. Después me convencí de que era incapaz de tener sentimientos amables para nadie. Cada día que lo trataba, reconocía la imposibilidad de ser sincero con él, porque él no lo era con nadie" (71). Queda de parte del otro la responsabilidad del fin de su amistad, hecho significativo pues la vigencia de Contemporáneos como grupo fue un momento en las letras mexicanas ligado a la aparición de la revista y a los proyectos colectivos que ya para los años setenta habían quedado atrás. ${ }^{7}$ Nandino (2000) concluye la valoración de su coetáneo: "indudablemente que si Salvador hubiera tenido respeto por sus amigos y si hubiera sido más sincero en la poesía, hubiera triunfado mucho. [...] Su prosa era limpia, ágil y convincente" (72). Más adelante insiste en ese sentimiento que le inspiraba, al afirmar que: "a Salvador Novo, queriéndolo y admirándolo mucho, también le tenía cierto odio porque nunca se medía para atacar a los demás" (84).

Resulta totalmente opuesta la descripción emocional hacia Villaurrutia. Desde el primer encuentro señala: "desde luego que me incliné más por la atracción de Xavier, porque noté que era discreto, educado y con cierta luminosidad de inteligencia" (59). En el capítulo consagrado a él deja clara su predilección: "Xavier era alegre; le gustaban tanto los cabarets de lujo como los de baja clase. Lo cierto es que de todos los del grupo era el más agradable, el más simpático y el que hipócritamente ${ }^{8}$, era el más sincero. En lo particular, yo lo admiraba" (65). Admite la influencia que tuvo en él pues, además de las recomendaciones de lecturas, le enseñó el rigor de la creación poética. Elías, por su parte, lo ayudó a desvanecer supersticiones como, por ejemplo, evadir a los ciegos o desmayarse al ver sangre, afirma que Villaurrutia "se fue humanizando" (56). Más aún, se percató que en la ronda de visita a los enfermos "a los muy pobres les deslizaba algunas monedas debajo de la almohada" (64).

$7 \mathrm{Al}$ exponer su versión de los acontecimientos de las letras mexicanas de aquellos años es claro al indicar: “Los 'Contemporáneos' desarrollaron sus actividades hasta 1931, cuando feneció su revista. El grupo lo componían estrictamente Villaurrutia, Novo, Jorge Cuesta, Gilberto Owen, José Gorostiza, Jaime Torres Bodet, Bernardo Ortiz de Montellano y Enrique González Rojo; agregados a ellos en continuo trato Salazar Mallén, yo, Agustín Lazo, quien fuera parte de la inteligencia medular que ellos aprovecharon, como hicieron con Octavio Barreda [...] Hago notar que también se agregó al grupo Carlos Pellicer." (61-62) 8 En la correspondencia publicada entre Novo y Villaurrutia se enteró de que la simpatía no era mutua, pues el segundo hacía el siguiente comentario: "El único que me escribe con frecuencia es Elías, pero ya ves cómo es Elías: no sabe si uno puede resistir su entrega" (69), observación dolorosa al considerarse Nandino un hermano del autor de Nostalgia de la muerte. 
En cuanto a la caracterización física realiza el siguiente retrato: "bajo de estatura, su rostro era cubista: una gran nariz y su risa lo partían en dos medios rostros, y tenía unos ojos grandes, con las pestañas muy largas" (65). Sobre su personalidad apunta: "era amable, educado y discreto; no hacía exhibición de su homosexualidad. Tenía excelente conversación; hábil para ofender sin hacer herida e inteligente para defenderse" (65). Nandino evidencia cómo la cultura se adquiere y en este caso según él la amistad de Agustín Lazo fue notoria para su conocimiento del teatro y pintura europeos.

Un lugar preponderante entre sus recuerdos ocupa la figura de Villaurrutia: "En honor a la verdad, fue el amigo con quien más congenié y a quien más quise" (66). Rememora un viaje a Tehuacán, famoso por sus aguas termales, donde cada uno fue con su respectiva pareja y gozaron de una "hermosa luna de miel" (106). No es de extrañarse entonces el efecto causado al enterarse sobre su muerte. Cuando leyó sobre ésta en un encabezado de un periódico en Córdoba, Veracruz, expresa: "sentí que me partieron longitudinalmente; desde ese momento me sentí incompleto" (67-68). Nadie remplazó el sitio que ocupara su más querido amigo. No obstante, quince días después, soñó que sostenía una conversación con él y se consoló a la mañana siguiente escribiendo unas décimas con las que curó aquella pérdida.

En el capítulo dedicado a revelar la atmósfera de "El Salón México", Nandino confiesa: "a Xavier y a mí nos gustaba ver esa hoguera lúbrica, y a él le gustaba mucho bailar, aprender pasos, y tenía mucha gracia para hacerlo" (147). De aquel episodio ninguno de los dos se fue con las manos vacías, Villaurrutia se marchó con un muchacho que "cuando reía, todo el rostro se le llenaba de risa" (147) y Nandino pasó el resto de la noche con un hombre "del tipo de Rodolfo Valentino" (148), con quien asegura haber pasado el más inimaginable gozo combinando el deseo con el miedo. La cercanía entre Elías y Xavier estaba sellada por la complicidad de sus exploraciones nocturnas en la Ciudad de México de aquellos años cuarenta ${ }^{9}$.

Al siguiente miembro del grupo al que le dedica más páginas es a Carlos Pellicer, quien fue secretario particular de José Vasconcelos e hizo

9 Véase Salvador Novo, La estatua de sal. Prólogo de Carlos Monsiváis. México, Consejo Nacional para la Cultura y las Artes, 1999. Una reseña mía apareció en Decires, no. 4, segundo semestre de 2001, pp. 109-111 (puede consultarse en línea en http://www.revistadecires.cepe.unam.mx/). 
fama en Colombia. Nandino lo recuerda como un "buen tipo, pero con calvicie prematura. Hablaba siempre dogmáticamente y leía sus poemas exaltando la potencia de su voz. A mí me dedicó dos poemas. Yo fui su amigo y su médico" (81). Insiste, el memorialista, en exhibir el paso de los años de sus antiguos compañeros: "lo vi en el Canal 13, como senador de la República, completamente avejentado, luciendo una calva en la que no había ni un solo pelo de tonto, en la que, como espejo, se reflejaba la luz, y secándose con un pañuelo la saliva. Me dolía que no tuviera pudor para presentarse así" (83).

Indirectamente, por medio del recuerdo de unas palabras de José Gorostiza, se elabora un juicio crítico sobre su obra: "una vez me dijo que los poemas de Pellicer eran como un racimo de globos de todos colores, que si tomaba el racimo y pasaba un cigarro en cada globo, nomás hacían 'pum' y no quedaba nada" (79). El propio Nandino señala que: "si un buen crítico hace el libro amoroso de Carlos Pellicer pensando que en donde dice 'ella' debe decir 'él', alcanzará una gran intensidad poética" (82). En un autoexamen expresa que tanto en su poesía como en la del tabasqueño hace falta realizar "un desmonte con machete airado y quitar todo el zacate y las breñas para [...] sacar a flote la verdadera maravilla" (82).

Del trato con José Gorostiza, rememora su "crítica aguda y certera" (79) y a una musa que trabajaba en un restaurante quien inspiró sus mejores versos de amor. Sobre su obra expresa desinterés, pues no lo considera poeta de primera línea y opina que Muerte sin fin es "apto únicamente para los eruditos" (80). Sobre su hermano, Celestino Gorostiza, aunque no lo considera parte de los Contemporáneos, lo valora como amigo y "hombre cabal y fino" (80).

A Jorge Cuesta le adjudica la responsabilidad de encumbrar Muerte sin fin, comenta su preferencia bisexual (61) y rotundamente señala: "como poeta no vale nada. Sus sonetos son duros, forzados y críticos" (75). No obstante, le da el papel de la conciencia del grupo, aunque piensa que los demás se aprovechaban de él como lo demuestra su firma de una antología de poesía moderna que apareció a su nombre cuando fue un libro colectivo. Los demás evadieron su responsabilidad pública con esta decisión. Desde su punto de vista tampoco como crítico era justo, pues "condenaba con facilidad y a los amigos los perdonaba con esa facilidad" (75). Nos pinta un carácter partidista. Reconoce su valentía al escribir 
política pues denunciaba los abusos del gobierno. Deja Nandino al lector en ascuas al finalizar el capítulo con esta frase: "su vida fue una tragedia y más vale no hablar de ella" (75).

De Gilberto Owen en el capítulo intitulado "Contemporáneos" anota que "era un poeta honesto y tenía interés en mi desarrollo" (Nandino 63). Agrega, al referirse particularmente a él, que "fue un hombre limpio y un amigo insuperable" (77). Sorprende, al respecto, ese vocablo referente a la limpieza, pues como consecuencia el resto adquiere un cariz de suciedad que puede ser interpretado en el ámbito moral como el de una conducta indigna, ya sea por su vínculo directo con Nandino o por su manera de relacionarse con el prójimo. Se subraya esa pureza del trato con la gente: "era amable y no hablaba mal de nadie" (77). Sobre sus poemas, indica "son verdaderas joyas" (77). Con dolor relata anécdotas de peligro debidas a su dipsomanía; Nandino acudió siempre a su ayuda. De tal modo, confía: "la amistad creció y realmente lo admiré por su poesía y por su manera de ser" (78).

A Jaime Torres Bodet también lo aprecia como amigo sincero y dice guardar gratos recuerdos de él, a pesar de que no le dedica un capítulo completo. ${ }^{10}$ Se conforma con apuntar que "su verdadero valor fue político porque desempeñó con honradez y acierto tanto el ministerio de Educación como el de Relaciones" (80). Reconoce en sus libros de ensayos "una prosa limpia y certera, indudablemente valiosa" (80), aunque en el trato literario se percata de que "era una paráfrasis de Enrique González Martínez" (80). De peculiar interés son las siguientes líneas que descubren la parte privada de su camarada: "lo conocí en el cine Venecia -que era un cine de mala fama-, con una gabardina inglesa en el brazo, cambiando más de asiento que interesándose en las películas" (80). Se sugiere aquí la visita a un lugar de alterne entre hombres que gustan de otros hombres. Antes lo califica de "reprimido" (61).

En este aspecto es relevante la personalidad de otro autor de la época, Porfirio Barba Jacob, pues en el caso de Nandino, éste lo considera como alguien cercano:

Había en él como un afán de destrozar su carne, para que quedara su alma pura y desnuda. Vivía el goce y el arrepentimiento de sus vicios. Yo adoro sus poemas porque mi caso es

10 Tampoco se ocupa de "Bernardo Ortiz de Montellano y Enrique González Rojo" (64), a quienes el autor señala que francamente no trató en su texto. 
semejante al de él: el de gozar y sufrir la pureza y la impureza que desgraciadamente se practica con las letrinas del cuerpo o cambiando las funciones de nuestros propios órganos. Nadie puede comprender el goce tan tremendo del amor contranatura y tener, al mismo tiempo, el remordimiento como una punzada dentro de la conciencia. (112)

Se trata de un momento de autodefinición, en el cual están claros sus gustos sexuales y donde, además, se aclara su postura al respecto. Ese espíritu gobernado por el deseo da muestra de su expresión en la palabra, en la cual lo corporal adquiere un sentido completo con la experiencia. Describe Nandino su función de hombre fuerte cuando después de las tertulias literarias exploraban la vida nocturna de la Ciudad de México: "nos cortábamos los parranderos y nos íbamos al 'Salón México', a la 'Playa Azul', al 'Tenampa' y a todos los sitios donde había vino, canto, golfos y oportunidades. A mí me llevaban como el halcón porque todos ellos eran orgánicamente débiles. Vida preciosa que llevamos por largos años" (61). Otro aspecto añorado es que "en el grupo hacíamos muchos juegos de ingenio literario en que hincábamos nuestras ironías" (83).

La franqueza del autobiógrafo es notoria al contar sus razones para no pertenecer del todo al grupo literario. Por un lado, pesaron motivos profesionales, pues en 1928 se fue a Estados Unidos a elaborar su tesis y al año siguiente estuvo preparándose para su examen profesional como médico. Por el otro, "porque desde un principio me marginaron, pensaron que era un diletante, que mi vocación poética solo era entusiasmo" (Nandino 63). Esa percepción quizá tenía fundamento al darle mayor importancia a sus estudios de medicina que a la creación literaria. El propio Elías reconoce: "yo admití su criterio porque nunca busqué obtener fama de la poesía. Lo que yo buscaba era orientación en la lectura, en la conversación, en el trato social y con mis amigos afines pasear y gozar nuestras aventuras. Iba de la provincia, fogoso, con un espíritu fresco, lleno de ansiedades" (63). Para él no eran incompatibles ambas actividades: "estudiaba con verdadero ahínco mi carrera y tenía un amor completo a mi poesía” (63). Sin embargo, se queja de la actitud desdeñosa hacia su obra:

publiqué mis libros en diferentes editoriales, sin buscar su crítica, y cuando ya estaban publicados, los ponía en sus manos. Siempre me mostraron un desinterés y una débil crítica, pero toda esa humillación fue vengada porque cuando todos ellos 
estaban muertos yo recibí el Premio Nacional y tuve el gusto de que mi obra resucitara y fuera vigente. (63) $)^{11}$

Se constata la visión apuntada en el capítulo consagrada a la visión de conjunto: "los 'Contemporáneos' hacían un círculo cerrado y querían llegar a puestos diplomáticos o vivir de las letras como empleados públicos para conquistar la fama. De ahí su egoísmo. Trabajaban para ellos mismos y los otros tenían que trabajar para ellos" (62).

No cabe extrañarse entonces que en términos generales, Elías Nandino aplique el juicio institucional de los nacionalistas al valorar al grupo sin grupo: "pecaron por desarraigados, se olvidaron completamente de la Revolución y, como buenos burgueses, trabajaron desde sus pupitres y criticaron dentro de los conceptos de su educación, con rezagos porfirianos" (64) ${ }^{12}$. Más adelante afirma que: "fue una especie de club en el que se trataban como en el cuento del periquito rey, con esa frase, y todos eran reyes" (75). En Juntando mis pasos intenta ser equilibrado: "a los 'Contemporáneos' los trato sin ningún respeto. Los admiro hasta donde se debe y los miro reales hasta en lo que no se debe. Yo fui su médico, conversé y anduve con ellos. Por eso hablo sin adornos y sin ambages" (85). Recuerda que en el estudio de Roberto Montenegro llegaron a la confianza plena (97).

En 1972 el jefe del Departamento de Bellas Artes del estado de Jalisco invitó a Nandino a abrir el primer taller de literatura en Guadalajara (153), lo cual hizo el poeta dedicando las primeras sesiones a analizar la labor del movimiento encabezado por Contemporáneos para desanquilosar las letras del occidente de México.

\section{Consideraciones finales}

Al contrastar los retratos literarios de Contemporáneos elaborados por Jaime Torres Bodet (1995) y Elías Nandino (2000), se aprecia la margi-

11 Además de obtener en México el Premio Nacional de Literatura en 1982, se instauró desde 1975 un Premio Nacional de Poesía Joven, con su nombre, "Elías Nandino", convocado por el Gobierno del Estado de Jalisco y el Instituto Nacional de Bellas Artes (INBA).

12 Para Octavio Paz (1994) dicha actitud más bien "fue una reacción ante ciertas experiencias de la vida mexicana. Niños, habían presenciado las violencias y las matanzas revolucionarias; jóvenes, habían sido testigos de la rápida corrupción de los revolucionarios y su transformación en una plutocracia ávida y zafia [...] Los poetas de Contemporáneos ya no podían creer ni en los revolucionarios ni en sus programas. Por eso se aislaron en un mundo privado poblado por los fantasmas del erotismo, el sueño y la muerte." (75). 
nalidad que tuvo este último con respecto al grupo, ya que debido a su longevidad es quizá más severo en la valoración crítica de la obra de sus compañeros. El contrapunto se hace notorio al tomar como referencia la figura de Porfirio Barba Jacob, pues mientras que el primero marca su distancia frente a quien considera un "inmoralista", el segundo se ubica cercano a aquella postura desafiante.

De tal manera, al hacer el balance, se aprecia como Carlos Pellicer es caracterizado por tener una mirada profunda y ofrecer una palabra cálida desde la perspectiva de Torres Bodet, quien además elogia su prodigio verbal al que señala como uno de los lujos de nuestro continente. Para Nandino, al contrario, su poesía amorosa pierde intensidad al ocultar su orientación homosexual y sugiere que hace falta seleccionar aquellos poemas de valía entre la vasta producción pelliceriana. Como persona lo estima como un buen tipo, aunque en la vejez haya aceptado una senaduría y apareciera en televisión exhibiendo las inmundicias de la edad. Lo mismo opina de Salvador Novo, al que describe como horrendamente feo: jorobado, calvo y barrigón, aunque reconozca su agudo sentido del humor y su prosa limpia, ágil y convincente. A Nandino le intranquiliza su atrevimiento al calificar de ridícula su jotería y apreciar la discreción de Xavier Villaurrutia, de quien admira la inteligencia luminosa, sus ojos grandes y pestañas muy largas. Sin duda, es su preferido al ser una persona alegre, simpática y caritativa. Si para Elías uno es la némesis del otro, para Torres Bodet actúan como un dúo.

Las divergencias continúan, mientras que para el primero Bernardo Ortiz de Montellano fue el más cercano y constante de sus amigos, para el otro no hubo suficiente trato para describirlo. Lo mismo sucede con Enrique González Rojo de quien Torres Bodet sí asienta su talante positivo y su experiencia viajera. Con Gilberto Owen sucede lo opuesto, Nandino lo califica de amigo insuperable que no hablaba mal de nadie y Torres Bodet apenas lo menciona como participante en una discusión sobre la poesía pura.

Son duras las críticas a la obra de Cuesta y Gorostiza por parte de Nandino, mientras que al último dedica Torres Bodet varias líneas explicando su afinidad poética basada en la importancia de los medios tonos, aunque reconozca que el autor de Muerte sin fin sí encuentra el ejercicio sutil de la palabra y él no. En el extremo opuesto, el poeta jalisciense piensa que esa obra poética es solo apta para eruditos. Únicamente Elías Nandino expresa su opinión abierta sobre el otro, al reconocer en Torres 
Bodet al político eficaz y honesto, aunque reprimido en su sexualidad e influido en su producción literaria por Enrique González Martínez.

Asimismo, se aprecia una función de la memoria distinta en cada caso. Aunque ninguno de los escritores pretende ser un biógrafo de sus pares, es decir, que no reconstruyen la trayectoria temporal de las personas retratadas, sí hay en la configuración de la presencia del individuo en Nandino una dimensión temporal que recoge la primera impresión de jóvenes y la transformación en adultos. En cambio, Torres Bodet conserva el aspecto intemporal de la estampa de sus compañeros.

La práctica del retrato literario en Tiempo de arena y en Juntando mis pasos ilustra la cercanía de sus autores con el grupo de Contemporáneos, quienes fueron valorados tanto de manera personal como literaria. Al trazar la vida de los otros en su conjunto, tanto Jaime Torres Bodet como Elías Nandino recrean el ambiente en que se desenvolvieron los integrantes de un grupo literario en un momento clave para las letras mexicanas del siglo XX.

\section{Bibliografía}

Castañón, Adolfo. “¿Homenaje o vasallaje?”. Los Contemporáneos y su tiempo. México, Instituto Nacional de Bellas Artes / Museo del Palacio de Bellas Artes, 2016, pp. 84-93.

Díaz Arciniega, Víctor. "El retrato literario. Una forma de crítica y creación”. En torno a la literatura mexicana. Mata, Oscar (coord.). México, Universidad Autónoma Metropolitana - Azcapotzalco, 1989, pp. 63-82.

Espinasa, José María. Actualidad de Contemporáneos. México, Ediciones Sin Nombre, 2009.

Fernández Perera, Manuel, coord. La literatura mexicana del siglo XX. México, Fondo de Cultura Económica; Consejo Nacional para la Cultura y las Artes ; Universidad Veracruzana, 2008.

Iriarte López, Margarita. El retrato literario. Navarra, Ediciones Universidad de Navarra, 2004.

Marchese, Angelo y Joaquín Forradellas. Diccionario de retórica, crítica y terminología literaria. Barcelona, Ariel, 2000.

Nandino, Elías. Juntando mis pasos. México, Editorial Aldus, 2000. 
Olea Franco, Rafael. "Jaime Torres Bodet: Tiempo de arena, tiempo de memorias. Los contemporáneos en el laberinto de la crítica. México, El Colegio de México, 1994, pp. 77-88.

Paz, Octavio. “Contemporáneos”. Generaciones y semblanzas. Dominio mexicano. Obras completas. Vol 4. México, Círculo de Lectores, Fondo de Cultura Económica, 1994, pp. 69-93.

Quirarte, Vicente. Perderse para reencontrarse: bitácora de Contemporáneos. México: Universidad Autónoma Metropolitana - Azcapotzalco, 1985.

Schneider, Luis Mario. “Los otros contemporáneos”. Los Contemporáneos y su tiempo. México, Instituto Nacional de Bellas Artes / Museo del Palacio de Bellas Artes, 2016, pp. 80-83.

Sheridan, Guillermo. Los Contemporáneos ayer. México, Fondo de Cultura Económica, 1993.

Toledo, Alejandro. "La literatura mexicana del siglo XX". Literatura. Historia ilustrada de México. Enrique Florescano, coordinador. México, Consejo Nacional para la Cultura y las Artes / Debate, 2014, pp. 215-269.

Torres Bodet, Jaime. “Tiempo de arena”. Obras escogidas. Poesía/ Autobiografía/Ensayo. México, Fondo de Cultura Económica, 1995, pp. 189-384. 